\title{
Ecuador TV como medio de propaganda en las elecciones presidenciales de la era Correa (2007-2017)
}

\author{
Ecuador TV as a means of propaganda in the presidential \\ elections in Correa's era (2007-2017)
}

\author{
Panchana-Macay, A. y Barrera, C. 1 \\ Recibido: 13-05-2021 - Aceptado: 05-08-2021 \\ https://doi.org/10.26441/RC20.2-2021-A17
}

RESUMEN: La creación, por vez primera en la historia de Ecuador, de una televisión como medio de comunicación de titularidad pública tuvo lugar en 2007 con Ecuador TV. Con el paso del tiempo se erigió en portavoz de la presidencia de Rafael Correa, cuyo mandato terminó en 2017, quien a su vez adoptó diversas medidas para el control de la información periodística tendentes a favorecer su mantenimiento en el poder. Además de Ecuador TV, se amplió notablemente el número de medios públicos e incautados, si bien la operadora televisiva fue el más determinante de todos ellos por su alcance geográfico y audiencia.

Este trabajo pretende demostrar, mediante la descripción del contexto político, jurídico y mediático y el estudio de un caso relevante, la importancia de Ecuador TV como medio de propaganda. Se procede a un estudio detallado del contenido de programas informativos de las tres campañas electorales presidenciales celebradas durante ese período. Se realiza a través de un análisis cuantitativo y cualitativo basado en diversos parámetros que permiten concluir la presencia de sesgos propios de la propaganda política, en este caso a favor del candidato oficialista y en contra de los rivales. Además de la bibliografía existente sobre estos temas, se ha entrevistado a diversas autoridades de los medios públicos y de las estructuras políticas controladoras de la información, que proporcionan enfoques de alto interés para apuntalar las conclusiones.

Palabras clave: Ecuador TV; medios públicos; Rafael Correa; propaganda; Ecuador; televisión.

ABSTRACT: Ecuador TV, launched in 2007, was the first public television channel in the history of Ecuador. As time went by, it was setting up as Rafael Correa's spokesperson until the end of his term of office in 2017. Correa took several measures in order to ensure the control of news media and favor his staying in power. Following this strategy, he increased the number of state-owned and confiscated media outlets, although Ecuador TV became the most determining due to its geographical scope and audience.

This article aims to show the significance of Ecuador TV as means of propaganda through both the description of political, juridical and media contexts, and a relevant case study based on a detailed content analysis of news programs covering the three presidential campaigns that took place during Correa's term of office. We use both quantitative and qualitative methods taking in consideration diverse variables that allows us to conclude the presence of biases usually linked to political propaganda in favor of the party's official candidate and against its rivals. Together with bibliography related to these topics,

\footnotetext{
${ }^{1}$ Allen Panchana-Macay es Doctor en Comunicación y Máster en Comunicación Política y Corporativa por la Universidad de Navarra. Además, es profesor titular de la Carrera de Comunicación de la Universidad Católica de Santiago de Guayaquil. Sus líneas de investigación se centran en los medios públicos, el análisis de contenidos y la relación de la política con la televisión. apanchana@alumni.unav.es, http://orcid.org/0000-0001-8510-3460

Carlos Barrera es Doctor en Comunicación y Profesor Titular de Periodismo en la Facultad de Comunicación de la Universidad de Navarra. Director Académico del Máster en Comunicación Política y Corporativa. Sus líneas de investigación se centran en la historia reciente de los medios de comunicación y su relación con la política, así como en la historia de la enseñanza y la investigación en comunicación. cbarrera@unav.es, https://orcid.org/0000-0001-9771-4074
} 
another source has been the interviews with directors and managers of state-owned media outlets and government departments in charge of communications, who provide interesting approaches to reach more accurate conclusions.

Keywords: Ecuador TV; public service media; Rafael Correa; propaganda; Ecuador; Television.

\section{Introducción}

Rafael Correa inició su mandato como presidente de Ecuador el 15 de enero de 2007 tras haberse impuesto en la segunda vuelta de las elecciones presidenciales, celebrada el 26 de noviembre de 2006, a su rival Álvaro Noboa, abanderando el Movimiento Alianza PAIS (Patria Altiva y Soberana). Situado en la estela de lo que ha venido en llamarse el "Socialismo del Siglo XXI", mostró pronto claras afinidades con regímenes de inspiración bolivariana como la Venezuela de Hugo Chávez, la Bolivia de Evo Morales y la Argentina de Cristina Fernández de Kirchner, todos ellos entonces en su apogeo político. Tras la aprobación de una nueva Constitución en 2008, sería reelegido dos veces más en los comicios de 2009 y 2013. En 2017, no pudiendo optar a un tercer mandato consecutivo, Alianza PAIS presentó como candidato oficialista a su vicepresidente Lenín Moreno, que también ganó y sucedió a Correa como presidente del país.

El canal Ecuador TV, de titularidad pública, comenzó sus operaciones de prueba el 29 de noviembre de 2007. En abril de 2008 sus emisiones fueron ya regulares. Suponía una novedad en la historia de los medios de comunicación del país, ya que se trataba de la primera televisión pública. Los canales que operaban hasta entonces eran todos ellos comerciales, de titularidad privada. Su creación había sido posible gracias a un decreto ejecutivo del 26 de septiembre de 2007, cuando se estableció "Tevecuador, Sociedad Anónima", cuyos socios fundadores fueron el Ministerio de Cultura, que poseía la mayoría con un $98 \%$ de las acciones, y la compañía pública de telefonía Andinatel S.A., que contaba con el 2\% restante (E. Arosemena, comunicación personal, 3 de febrero de 2020). Posteriormente, en agosto de 2008, modificó su denominación por la de Televisión y Radio de Ecuador, S.A. (RTVEcuador), para ampliar así el espectro de su fin social a la radiodifusión y actividades afines (Mier, 2015).

El artículo 1 del Reglamento Interno de la nueva emisora televisiva manifestaba que era función del canal "proveer a la ciudadanía una programación entretenida y educativa a la vez que permite informar con imparcialidad y ética profesional". En el espíritu de su creación resaltaba su orientación a "la promoción ciudadana e intercultural" (Mier, 2015, p. 147) que diera visibilidad a los actores sociales que no habían tenido espacio en la televisión comercial. La titular de la Secretaría de Comunicación (Secom), Mónica Chuji, una de las personas encargadas de ponerla en marcha, la definió como "una entidad pública con gestión y operación autónoma (...) bajo la responsabilidad de un consejo directivo compuesto por representantes gubernamentales y de la sociedad civil". Para justificarlo, añadía que "la comunicación no es un privilegio de las empresas de medios, sino un derecho de los pueblos" (Mier, 2015, p. 146). Desde una perspectiva crítica, Ricaurte (2009) vio en Ecuador TV carencias de proyecto, "sin un estatuto de funcionamiento que garantizara libertad de gestión, claridad jurídica, línea editorial independiente" (párr. 2).

Desde el punto de vista operativo, el asociado principal de la operación fue Telesur, el canal público de televisión de la Venezuela presidida por Hugo Chávez, merced a una inyección financiera de cinco millones de dólares no reembolsables para la puesta en marcha de Ecuador TV (De la Torre, 2013) y al asesoramiento de algunos de sus directivos que participaron en el montaje efectivo del nuevo canal público, "con la intención de propagar en el continente la política socialista" (A. Manrique, comunicación personal, 4 de enero de 2020). El día de su inauguración oficial, el presidente Correa aseguró en una entrevista que era "un día feliz para todos porque al fin tenemos una televisión pública que no pertenece a manos privadas y, en consecuencia, no defiende a sus intereses" 
porque "a los canales privados les resulta complicado empatar sus intereses con los de la sociedad"; e instaba a la ciudadanía a "vigilar si la televisión pública está informando o realizando propaganda a favor del gobierno". (El Universo, 29 de noviembre de 2007). A ojos de los competidores privados, no se ocultaba que el equipo de campaña de Correa en 2006 consideraba "de alta estrategia política y comunicacional” (A. Sánchez, comunicación personal, 15 de octubre de 2019) la creación de una radiotelevisión pública para sus propósitos de gobierno.

Pronto comenzó a ampliar su cobertura, inicialmente restringida a las grandes ciudades por UHF. La banda VHF se hallaba ocupada históricamente, desde los años sesenta del siglo XX, por los distintos canales privados: Ecuavisa, RTS, Teleamazonas, Gamavisión, TC Televisión y Canal Uno. Con la migración posterior de transmisores UHF a la frecuencia VHF, en 2012 Ecuador TV llegó a alcanzar al 72\% de la población del país (M. Moncayo, comunicación personal, 25 de noviembre de 2019).

En términos generales, en América Latina las empresas privadas habían sido el actor principal en el desarrollo económico y tecnológico del sector televisivo y radiofónico. Los medios estatales que surgieron lo hicieron frecuentemente a la sombra de los distintos gobiernos. La proliferación de dictaduras y golpes militares hizo que su credibilidad y prestigio fueran habitualmente bajos entre la población al aparecer como portavoces de los gobernantes de turno (Mastrini, 2011) o con un tinte oficialista lejano del servicio público entendido al modo de las grandes corporaciones radiotelevisivas de Europa occidental (Ortega, 2010; Becerra y Waisbord, 2015).

Aun así, a diferencia de la mayoría de países de América Latina, no existía en Ecuador tradición de televisiones públicas. Junto con Paraguay, era el país de la región con menor presencia del Estado en el sector de la comunicación (Checa-Godoy, 2012; De la Torre, 2013). Si en la televisión no aparece hasta 2007 con Ecuador TV, en el ámbito radiofónico hubo que esperar hasta 1961 cuando se creó Radio Nacional. Bajo distintas normativas anteriores, como la Ley Básica de Telecomunicaciones de 1972 y la Ley de Radiodifusión y Televisión de 1975, el Estado aparecía como dueño de las frecuencias electromagnéticas y encargado de concederlas a personas naturales y jurídicas. En la reforma de esta última ley en 1995, se introdujeron artículos referidos a las estaciones de servicio público y sin fines utilitarios, a las que les estaba vedada la publicidad comercial.

Al mismo tiempo que el nacimiento de la televisión pública, los mandatos presidenciales de Correa promocionaron activamente la creación de otros medios públicos de comunicación y se adoptaron diversas medidas, entre ellas la incautación de medios privados, supuestamente para un control de la información periodística que tendiera a favorecer su mantenimiento en el poder.

Es objetivo de este trabajo demostrar, mediante la descripción del contexto político, jurídico y mediático y el estudio de casos, la importancia capital de Ecuador TV como medio al servicio de los intereses políticos de Rafael Correa. Se parte específicamente de la hipótesis de que fue un instrumento de propaganda para sus sucesivas victorias en las elecciones presidenciales. Estas proporcionaron una continuidad a su obra política basada en el eslogan "Revolución Ciudadana", utilizado en la campaña con la que accedió al poder en 2007 y cuyas iniciales coincidían con las del propio candidato.

Para abordar esta tarea se realiza un análisis de contenido de los programas informativos de las tres campañas electorales presidenciales celebradas en 2009, 2013 y 2017, con base en diversos parámetros que permitan concluir la presencia o no de sesgos propios de la propaganda política, en este caso a favor del candidato oficialista. Se ha consultado asimismo la bibliografía existente sobre estos temas, y se ha entrevistado a diversas autoridades de los medios públicos y de las estructuras políticas controladoras de la información, que proporcionan enfoques de alto interés para precisar los hechos y apuntalar las conclusiones. Entre ellos figuran Fernando Alvarado, ex titular de la Secretaría de Comunicación; Martha Moncayo, ex gerente de Medios Públicos EP; 
Enrique Arosemena, ex gerente general de Ecuador TV; Ángel Sánchez, ex director de TC Televisión; y también las versiones sobre el tema del ex presidente de Ecuador, Rafael Correa.

Por propaganda entendemos, con Jowett y O’Donnell (2012), “el intento deliberado y sistemático de dar forma a las percepciones, manipular cogniciones, y dirigir el comportamiento para lograr una respuesta que promueva la intención deseada del propagandista" (p. 7). En esta definición se pone el énfasis en que se trata de un desarrollo preciso, metódico y organizado de medios para alcanzar un fin. La propaganda va más allá de la mera persuasión debido a su alcance y sus consecuencias pues intenta hacerse con el entero control de las personas a través de una única interpretación de lo que se conoce (Ellul, 1973). Es, por lo tanto, "amplia en su alcance y debe dominar el mensaje en los medios convencionales" (Souls, 2015, p. 3). Desde un plano más filosófico, Cunningham (2002) apunta que la propaganda es "falsificación o pseudocomunicación" (p. 178) debido a sus serias deficiencias epistemológicas con respecto a valores como la verdad, la veracidad, la comprensión y el conocimiento.

En su largo recorrido histórico, la propaganda ha utilizado diferentes medios e instrumentos, pero los de naturaleza audiovisual se han mostrado especialmente efectivos. El poder de las imágenes suele otorgar mayor credibilidad y veracidad y provoca más fácilmente respuestas de tipo emocional (Jowett, 2008). Diversos autores han profundizado con fuerza, desde mediados del siglo XX, en conceptos como la psicología de la imagen (Goodman, 1976; Werner y Kaplan, 1963), la teoría del cultivo (Gerbner, 1970) o la aguja hipodérmica (Lasswell, 1927). Han demostrado, entre otros aspectos, la influencia de la televisión en la cultura, la carga simbólica y lo que esa simbolización implica: un "acto intencional de referencia denotativa" (Werner y Kaplan, 1963, p. 21). La aparición de la televisión a mediados del siglo XX supuso, en este sentido, un instrumento de gran impacto para llegar a un público masivo, de forma tal que pronto se convirtió en el medio propagandístico por excelencia, al igual que lo fue para la publicidad comercial.

Dependiendo de los criterios que se tomen, la propaganda puede revestir distintas formas. Atendiendo a su contenido, algunos autores distinguen entre propaganda blanca, gris y negra, según lo distribuido sea información veraz, pero de dudosa calidad, al evitar la identificación de la fuente, o simplemente falsa con intención de engañar, respectivamente (Wilke, 2008). En la propaganda blanca, que tiende a asimilarse con la publicidad, no suele ocultarse la fuente si bien la información puede darse de forma sesgada o distorsionada. A diferencia de esta, la gris y la negra no identifican sus fuentes. Si se toman en consideración los argumentos o modos de apelación, la propaganda puede ser racional o emocional. Es racional cuando se presenta con ropajes científicos, basada en hechos y con sentido aparentemente realista, y emocional cuando se apela a los sentimientos a través de creencias y mitos construidos que se proponen (Marlin, 2002).

\section{Correa y los medios de comunicación en su contexto político}

El triunfo de Correa en las elecciones presidenciales de 2007 como candidato de Alianza PAIS fue posible gracias a una campaña de fuerte cariz personalista y a un programa de gobierno cercano al llamado "Socialismo del Siglo XXI" o nueva izquierda latinoamericana (Natanson, 2010; Souza, 2010; Albán, 2016). Este nuevo socialismo se inspiró en el movimiento alentado y liderado por el presidente venezolano Hugo Chávez (1999-2013) y su denominada "revolución bolivariana". Como en casi todos los países que vivieron episodios semejantes, las reformas institucionales que se llevaron a cabo enfatizaron el papel del Estado como regulador y productor, contraponiendo la reivindicación de la sociedad civil como espacio político a los intereses económicos privados presentes en muchos sectores, entre ellos el de los medios de comunicación (Badillo, Mastrini y Marenghi, 2015).

Rafael Correa se presentó como un outsider de la política con formación de economista académica y, a la vez, como fustigador de la vieja y desprestigiada clase política. Mediante un cuidadoso uso de 
la comunicación, ya desde la campaña y extensivo luego a su período de gobierno, se autodefinió, en palabras de Kitzberger (2010), como "el hombre nuevo, libre de vínculos con las élites sociales y políticas, cercano al pueblo, y como alguien dispuesto a revertir una larga era de dominación de intereses minoritarios" (pp. 73-74).

Esa buscada confrontación con las élites (Conaghan y De la Torre, 2008) se dejó sentir enseguida en su relación con los medios de comunicación, la mayoría de ellos privados, que a su juicio estaban "del otro lado de la orilla" (Ramos, 2010), es decir, junto a los adversarios políticos a quienes había derrotado en las urnas. Los primeros episodios de enfrentamiento tuvieron como marco el anuncio presidencial de crear una Asamblea Constituyente para redactar una nueva Constitución, que conllevó la expulsión de 57 diputados de la oposición. Un editorial del diario La Hora, titulado "Vandalismo oficial", le valió a su director una querella oficial presentada por la Presidencia. Corría el mes de marzo de 2007. La nueva Constitución fue finalmente aprobada en referéndum el 28 de septiembre de 2008.

Este respaldo amplio (un 63,93\% de los votantes dieron el sí al nuevo texto) permitió a Correa emprender diversos proyectos en ámbitos variados de la vida política ecuatoriana, incluidos los medios de comunicación. Quien fue su jefe de campaña, Fernando Alvarado, nombrado secretario general de la Administración Pública, quedó a cargo de la estrategia mediática que siguió desde el gobierno, centrada en tres ejes principales: 1) comerciales de televisión para informar qué hacía el gobierno con el dinero del pueblo, en los que no aparecía Correa; 2) comerciales de contenido emocional, que buscaban generar cambios de conducta, en los que sí aparecía el presidente; y 3) información que promovía la visión del gobierno a través de cadenas nacionales, enlaces radiales y medios públicos (Ramos, 2010).

Para fortalecer este tercer eje, se creó el programa semanal Enlace Ciudadano, similar al Aló Presidente de Hugo Chávez, transmitido por las radios cada sábado y de unas tres horas de duración. A partir de las emisiones regulares de Ecuador TV en abril de 2008 también se transmitieron a través de su señal. Eran conocidas popularmente como las sabatinas. Sus detractores le acusaron de usarlas para "vapulear a sus opositores en vivo y en directo, pues llegó a exhortar a sus seguidores a tomar la justicia por su mano y presentó fotos de periodistas, activistas y políticos opositores para que fueran identificados" (Stornaiolo, 2019, p. 52). Se refería frecuentemente, entre sus enemigos, a la "oligarquía" y a la "prensa servil" sujeta a sus intereses, pues consideraba que no existía una "prensa libre, independiente, responsable, competente, veraz" en Ecuador (Zepeda, 2010). Entre 2007 y 2017, el presidente Correa hizo 523 enlaces ciudadanos, que contribuyeron a "la construcción de un personaje idolatrado por parte de la población" (Stornaiolo, 2019, p. 58). En sus ataques a los medios de comunicación críticos abundaron los insultos tales como "prensa mercantilista", "corrupta", "inmoral", "manipuladora", "falta de ética", "canallas", "amarillistas", "bocones", "buitres", "cínicos", "chismosos", “desequilibrados", "sicarios de tinta” (Stornaiolo, 2019, p. 52).

Estas prácticas no hubieran sido posibles sin la correspondiente y paralela legislación que los gobiernos de Correa fueron creando para potenciar su acción comunicadora y disminuir la de los medios opositores. A través de distintos mecanismos normativos se organizó un nuevo modelo de comunicación pensado desde el Poder Ejecutivo, se tejieron las estructuras de censura y control de los medios privados, y se dio paso al surgimiento acelerado de medios públicos que los contrarrestaran.

Aunque la Constitución de 2008 proclamaba el derecho a la libertad de expresión y el fomento de la pluralidad y garantía de creación de medios, tanto públicos como privados y comunitarios, el artículo 312 prohibió la participación de "entidades o grupos financieros, sus representantes legales [y] miembros de sus directorios y accionistas" en el control del capital o de la inversión en medios de comunicación. Un total de 118 accionistas de bancos, que poseían 201 participaciones en medios, se vieron obligados a vender y desvincularse del sector (Checa-Godoy, 2012). Rafael Correa ha asegurado que estas reformas eran necesarias porque "cinco de los siete canales nacionales de 
Ecuador pertenecían a la banca" (R. Correa, comunicación personal, 7 de abril de 2020), en clara referencia a Teleamazonas, Gamavisión, TC Televisión, Sí TV y Telerama.

Particular relevancia adquirió la incautación gubernamental de los medios propiedad de los banqueros hermanos Roberto y William Isaías, entre los que se encontraban TC Televisión y Gamavisión, amén de TV Cable y varias revistas de la editorial Uminasa. La incautación se decidió en una reunión de dieciséis horas en el Palacio Presidencial, que empezó la mañana del 7 de julio de 2008 (L. Cucalón, comunicación personal, 16 de enero de 2020). En la madrugada del 8 de julio, la Presidencia emitió un comunicado para respaldar el asalto a diferentes empresas -no solo periodísticas- a cargo de cientos de policías, militares y personal de la Agencia de Garantía de Depósitos. Los medios incautados fueron una importante maquinaria de propaganda "aprovechada por el régimen de Correa para reconfigurar la opinión pública y lograr, por ejemplo, las victorias en once procesos electorales que hubo en la década que gobernó (2007-2017), cuando entonces Alianza PAIS era imbatible políticamente" (A. Sánchez, comunicación personal, 15 de octubre de 2019).

Fruto también de la Constitución y su disposición transitoria vigesimocuarta, se creó una comisión encargada de auditar las concesiones para radio y televisión surgidas de la reforma de la Ley de Radio y Televisión en 1995. El informe, de 18 de mayo de 2009, subrayó numerosas irregularidades que redundaron, en especial, a favor de los integrantes del ente otorgador de las licencias, distintos partidos políticos y medios impresos.

Asimismo, el artículo 315 señalaba que el Estado constituiría "empresas públicas para gestionar sectores estratégicos [y] la prestación de servicios públicos". Así fue como la Asamblea Nacional, de mayoría oficialista, consideró la comunicación como servicio público, al igual que los transportes, "lo que podía eventualmente permitir un mayor control a la información desde los medios de comunicación, en especial de los independientes o la llamada prensa crítica" (A. Manrique, comunicación personal, 4 de enero de 2020). La Ley Orgánica de Comunicación (LOC), aprobada en junio de 2013, hablaría ya en su artículo 5 del "servicio público de comunicación masiva”, independientemente de la naturaleza pública, privada o comunitaria de la propiedad de los medios impresos y audiovisuales. Dos años y medio después, en diciembre de 2015, una reforma del artículo 384 de la Constitución elevó esa definición a mandato constitucional (F. Alvarado, comunicación personal, febrero de 2020), al establecerse que "la comunicación como un servicio público se prestará a través de medios públicos, privados y comunitarios".

Tomando como base el artículo 384 de la Constitución, que establecía la facultad del Estado para formular la política pública de comunicación, comenzó a delinearse desde el Ejecutivo un proyecto para regular este sector. Desde su anuncio fue visto como una amenaza a la libertad de expresión por diferentes actores. En mayo de 2011 se consultó a los ecuatorianos si estaban de acuerdo en que la Asamblea Nacional expidiera una Ley de Comunicación que regulara la difusión de contenidos de la televisión, la radio y la prensa. Ganó el sí con el 51,67\% de votos, y este resultado dotó de legitimidad popular a ese plan de gobierno.

Dicha ley servía de marco legal para los medios privados, públicos y comunitarios, a quienes se asignó, respectivamente, una participación del 33\%, 33\% y 34\% del espacio radioeléctrico, que distaba mucho de la realidad entonces existente, abrumadoramente en manos privadas. Particular significación del afán controlador de la actividad periodística tuvo la creación, mediante esta nueva normativa, del Consejo de Regulación y Desarrollo de la Información y Comunicación (Cordicom), y de la Superintendencia de la Información y Comunicación (Supercom). Sus facultades, que incluían la capacidad de vigilancia, auditoría y sanción, se tradujeron en numerosos conflictos con medios y periodistas del sector privado, que sufrieron sus decisiones en forma de amonestaciones, multas y suspensiones o clausuras (Suing, 2011; Checa y Barredo, 2016). 


\section{Ecuador TV y las campañas presidenciales de 2009, 2013 y 2017}

\subsection{Consideraciones generales y metodológicas}

Al finalizar el gobierno de Correa, en 2017, existían 51 medios inscritos como públicos, a los que habría que añadir una decena más de incautados, que quedaron también bajo control estatal. Las cifras no se correspondían del todo con la realidad dado que el Registro Público de Medios contenía bastantes inexactitudes y ambigüedades (Panchana y Mena, 2020). De entre todos los medios públicos creados o incautados, Ecuador TV fue, sin duda, el principal, tanto por los recursos económicos utilizados como por su pretensión inicial, conseguida en alto grado, de alcanzar toda la geografía del país como medio nacional por excelencia. Además, como señalaba un estudio de Fundamedios (2010), el 55,3\% de habitantes de Quito y el 70,3\% de Guayaquil preferían la televisión para informarse. Así, aunque se crearon otros medios públicos de muy diversa naturaleza y alcance (la mayoría regionales, provinciales o locales), Ecuador TV se erigía como el buque insignia de todos ellos, especialmente porque le estaba asignado un rol central como medio difusor oficialista, tal y como declaraban sus impulsores.

El 29 de diciembre de 2009, RTVEcuador pasó a configurarse jurídicamente como Empresa Pública, previa aprobación dos meses antes de la Ley Orgánica de Empresas Públicas. Años más tarde, el 22 de agosto de 2016, se conformó una nueva empresa, Medios Públicos EP, que dio forma y sinergias a la extensa red mediática gubernamental. En los spots televisivos e incluso en su mensaje de bienvenida, se presentó como "el holding de medios de comunicación más grande del Ecuador", dado que significaba la unión del incautado diario El Telégrafo, Ecuador TV y Radio Pública en una misma estructura societaria.

Ecuador TV contó desde sus inicios con una programación informativa nacional e internacional, documentales, cortos y largometrajes realizados en el país. Sus temáticas eran diversas: educativa, infantil, juvenil, deportes, artes populares y musicales y protección del medio ambiente. Además, por este medio se realizaban transmisiones de la Asamblea Nacional y del Enlace Ciudadano de la Presidencia de la República, los sábados (Mier, 2015). El área de noticias tenía una estructura vertical, presidida por el Director de Noticias, "que recibía recomendaciones de las autoridades del Gobierno para elaborar los contenidos” (Maldonado, 2017, p. 43).

Con el fin de corroborar la hipótesis, que los hechos históricos de su configuración parecen inspirar, de que Ecuador TV se convirtió en altavoz de la propaganda de los gobiernos de Correa, analizamos su línea informativa en las principales elecciones celebradas, es decir, las presidenciales. Mediante el análisis de contenido de los informativos de Ecuador TV previos y posteriores al día de los comicios, se obtienen resultados acerca de posibles sesgos progubernamentales en ellos. Lo realizamos con técnicas de medición tanto cuantitativas, que ponen el énfasis en la frecuencia de aparición de ciertas características, como cualitativas, es decir, que fijan su atención particularmente en la presencia o ausencia de determinadas características.

Los espacios informativos constituyen una fuente fundamental para la construcción de la opinión pública, de ahí que nos preguntemos por cómo construyó la realidad Ecuador TV a través de las noticias en esos días clave y si se convirtió en un instrumento de propaganda gubernamental o, por el contrario, procuró mantenerse al margen de posturas oficialistas en sus piezas informativas.

La complejidad de analizar el universo de noticieros del canal público a lo largo de la década de Correa (2007-2017), nos llevó a delimitar la unidad de análisis a los informativos emitidos en momentos clave dentro de ese periodo: los procesos electorales, que suelen ser los momentos más significativos y trascendentales desde los puntos de vista informativo y político. Correa ganó su primera elección presidencial el 26 de noviembre de 2006. Sin contar esta fecha, Ecuador tuvo once 
comicios en ese periodo. Tres de ellos, en los cuales nos enfocamos, fueron presidenciales: los de 2009 y 2013, en los que Rafael Correa fue candidato a la reelección y ganó en primera vuelta, sin necesidad de balotaje porque obtuvo más del 50\% de los votos; y el de 2017, cuando Correa y su aparato estatal apoyaron la candidatura del oficialista Lenín Moreno, y su posterior balotaje frente al candidato Guillermo Lasso.

Se escogieron los telediarios de Ecuador TV de su horario prime time a las nueve de la noche, y más particularmente los contenidos sobre Actualidad, Política e Internacionales. Se excluyeron los relacionados con Entretenimiento y Deportes por no ser relevantes para el análisis debido a sus temáticas. Los telediarios seleccionados como muestra corresponden al último día de campaña (jueves) y al día posterior a la elección (lunes). La campaña termina los jueves. Son, según la Ley Electoral, la última oportunidad para manifestarse a plenitud previo al silencio electoral obligatorio que rige viernes y sábado para todos los ciudadanos e instituciones del país, incluyendo los medios de comunicación, setenta y dos horas antes de la elección que se realiza en domingo. Por su parte, los telediarios de los lunes se hacen eco de los resultados y de sus posibles valoraciones.

Suele considerarse que la muestra previa y posterior a la fecha de un evento programado -en este caso unas elecciones- es representativa para obtener un análisis más claro (Ortega y Galhardi, 2013) En todo caso, debe conseguirse un mínimo de unidades de análisis sobre un volumen de noticias suficiente. Además, las muestras previa y posterior resultan más significativas, al analizar los contenidos de un canal televisivo, que las del mismo día de un proceso electoral dado que sus informativos suelen ser continuos desde primera hora de la mañana y no, per se, una emisión en el prime time.

La literatura sobre la técnica de análisis de contenido recoge la importancia de elaborar una serie de parámetros o categorías para detectar dentro de los mensajes aquellos rasgos que interesan en la investigación (Páramo-Bernal, 2018). En este caso, se revisaron 37 variables que han sido empleadas en estudios que analizan productos emitidos por telediarios. De ellas se escogieron finalmente 14 porque resultaron relevantes y más acordes a los fines del presente trabajo. Como se observa en la Tabla 1, estas variables incluyen elementos para el análisis de forma y ciertos códigos para el análisis de fondo.

Tabla 1. Ficha de las variables y su descripción.

\begin{tabular}{|c|c|}
\hline Variable & Descripción y códigos \\
\hline Tema & Tema concreto al que se refiere la nota. \\
\hline Pieza & Segundos de noticia. Contabilizado como tiempo de narración audiovisual. \\
\hline Relevancia & $\begin{array}{l}\text { Indica el grado de actualidad de la noticia. Es: } \\
\text { 1) Tópica si hace referencia a eventos actuales o periódicos (aniversarios, rebajas, etc.) } \\
\text { 2) Intemporal si no está ligada a la actualidad y podría haberse emitido cualquier otro día. }\end{array}$ \\
\hline Contextualización & Indica si la noticia está suficientemente explicada en sus antecedentes. \\
\hline $\begin{array}{l}\text { Criterios de } \\
\text { interés } \\
\text { (Coyuntura) }\end{array}$ & $\begin{array}{l}\text { Se refiere a los criterios de selección de la noticia explicitados por los informadores, es- } \\
\text { pecialmente en la entradilla. Estos son: } \\
\text { 1) Actualidad: Ocurrido recientemente (alusiones del tipo "esta tarde", "hoy", etc.). } \\
\text { 2) Proximidad: ocurrido en el lugar cercano o sentido culturalmente cercano (alusiones } \\
\text { del tipo "cerca de aquí", "en nuestro país", etc.). } \\
\text { 3) Rareza: poco corriente, inusual. } \\
\text { 4) Conflicto: controversia, polémica, disputa. } \\
\text { 5) Notoriedad pública: con relevancia social. } \\
\text { 6) Alusión a lo personal: alude a situaciones de personas concretas ("una persona queri- } \\
\text { da"). } \\
\text { 7) Interés formal: alude al interés de las imágenes o sonidos en sí mismos (alusiones del } \\
\text { tipo "imágenes espectaculares"). } \\
\text { 8) Concienciación social: si se refiere a la educación del ciudadano o a la implicación } \\
\text { social. }\end{array}$ \\
\hline
\end{tabular}




\begin{tabular}{|c|c|}
\hline Enfoque & $\begin{array}{l}\text { Es la orientación o el marco en que se encuadra la noticia. Se puede codificar como: } \\
\text { 1) Enfrentamiento: resalta el carácter conflictivo de la situación o los participantes. } \\
\text { 2) Conjetural: la noticia se enfoca desde una perspectiva especulativa. } \\
\text { 3) Histórico: punto de vista explicativo del proceso o cómo evoluciona. } \\
\text { 4) Perspectivista: cómo puede repercutir el hecho en el futuro. } \\
\text { 5) Consensual: enfoque que resalta los puntos de acuerdo en torno a un tema o lo suce- } \\
\text { dido. } \\
\text { 6) Competitivo: quién tiene una posición ganadora y quién va perdiendo. } \\
\text { 7) Denunciador: noticia enfocada desde la denuncia de una injusticia o error. } \\
\text { 8) Documental: se ofrece una visión realista de la noticia mediante declaraciones o infor- } \\
\text { mación. } \\
\text { 9) Reactivo: basada en la respuesta o reacción de los principales protagonistas. } \\
\text { 10) Interés humano: punto de vista emotivo. } \\
\text { 11) Actual: enfoque que acentúa la modernidad o acorde con la moda de un tema. } \\
\text { 12) Policial: punto de vista de la investigación de la policía y su impacto. } \\
\text { 13) Personal: enfoque subjetivo del redactor, periodista, presentador. }\end{array}$ \\
\hline Base de la noticia & Se refiere a si la información emitida se basa en: 1) hechos; o 2) conjeturas. \\
\hline $\begin{array}{l}\text { Actitud/tono } \\
\text { del narrador }\end{array}$ & $\begin{array}{l}\text { Indica la actitud del narrador de la información tanto en el lenguaje como en los gestos. } \\
\text { Puede ser: 1) positiva: ensalza un hecho o persona; } \\
\text { 2) negativa: desluce o desfavorece un hecho o persona; o 3) neutra. }\end{array}$ \\
\hline $\begin{array}{l}\text { Indicio de } \\
\text { propaganda }\end{array}$ & $\begin{array}{l}\text { Indica si la noticia tiene interés promocional o si contiene propaganda. Puede ser: } \\
\text { 1) Blanca: no oculta su fuente y es sesgada; } \\
\text { 2) Gris: de dudosa calidad, no identifica la fuente; } \\
\text { 3) Negra: falsa, con intención de engañar, no identifica su fuente. }\end{array}$ \\
\hline Fuentes & $\begin{array}{l}\text { Recoge el tipo de fuentes usadas en la noticia, si las hay. Pueden ser: } \\
\text { 1) Implícitas: cuando se nombra una fuente genérica ("fuentes consultadas por nuestra } \\
\text { cadena..."). } \\
\text { 2) Explícitas: cuando la fuente es nombrada de forma directa o indirecta ("según Juan } \\
\text { Pérez"). } \\
\text { 3) Originaria: fuente que da origen a la información (comunicado del Gobierno, un } \\
\text { convocante de una manifestación, un juez...) que generalmente busca o convoca a los } \\
\text { medios. } \\
\text { 4) Implicada/interesada: cuando la fuente tiene parte en la información y puede ser ses- } \\
\text { gada porque no es imparcial (declaraciones de un criminal o su familia, un juez, defensa } \\
\text { de una ley por el propio Gobierno, etc.). } \\
\text { 5) Consultada: fuente buscada expresamente por el medio de comunicación para buscar } \\
\text { contraste o profundidad a la información. } \\
\text { 6) Equilibradas: si se buscan fuentes de todos los implicados en la información. } \\
\text { 7) Expertas: si la fuente a la que se acude es experta en la materia. } \\
\text { 8) Encuestados: se usa como fuentes a viandantes o personas corrientes para dar cuen- } \\
\text { ta de una opinión generalizada. } \\
\text { Estos tipos no son mutuamente excluyentes. Una misma fuente puede ser consultada, } \\
\text { experta y equilibrada, por lo que el número de selecciones no se corresponde con el nú- } \\
\text { mero de fuentes. }\end{array}$ \\
\hline Imágenes & $\begin{array}{l}\text { Imágenes que acompañan a la información, las más significativas. Pueden ser de carác- } \\
\text { ter: } \\
\text { 1) positivo: si ensalza un hecho o persona; } \\
\text { 2) negativo: si desluce o desfavorece un hecho o persona; o 3) neutro. }\end{array}$ \\
\hline $\begin{array}{l}\text { Palabras con carga } \\
\text { semántica añadida }\end{array}$ & $\begin{array}{l}\text { Palabras o expresiones cuyo significado denotativo se ve distorsionado por las implica- } \\
\text { ciones emocionales. }\end{array}$ \\
\hline Adjetivaciones & $\begin{array}{l}\text { Se recogen las calificaciones aplicadas a los principales actores de la noticia, así como a } \\
\text { las temáticas más relevantes, bajo la cualidad de: } \\
\text { 1) positiva: si ensalza un hecho o persona; } \\
\text { 2) negativa: si desluce o desfavorece un hecho o persona; o 3) neutra. }\end{array}$ \\
\hline Protagonismo & $\begin{array}{l}\text { Incluye el tiempo de cita directa y, si hay cita indirecta, de los principales actores de las } \\
\text { noticias. }\end{array}$ \\
\hline
\end{tabular}

Fuente: Elaboración propia con base en Marlin (2002) y Wilke (2008). 
A partir de los ocho telediarios del prime time escogidos para esta investigación, se obtuvo una muestra total de 95 piezas informativas para el análisis (Tabla 2). Cada nota se ubicó dentro de una matriz con sus respectivos datos de registro (fecha, número de nota y tema), acompañados de las variables antes mencionadas y la codificación respectiva. La sistematización, además de la revisión de los videos correspondientes a cada pieza informativa, incluyó la transcripción de las narrativas para el análisis cualitativo de los mensajes. El material audiovisual suma en total 6 horas y 40 minutos. Las emisiones informativas revisadas tienen una duración que oscila entre 25 y 40 minutos.

Tabla 2. Muestra escogida para el análisis de contenido.

\begin{tabular}{|c|l|c|}
\hline \multirow{2}{*}{ Año } & \multicolumn{1}{|c|}{ Fecha } & $\begin{array}{c}\text { Número } \\
\text { de piezas }\end{array}$ \\
\hline \multirow{2}{*}{2009} & Jueves, 23 de abril & 8 \\
\cline { 2 - 3 } & Lunes, 27 de abril & 4 \\
\hline \multirow{2}{*}{2013} & Jueves, 14 de febrero & 11 \\
\cline { 2 - 3 } & Lunes, 18 de febrero & 16 \\
\hline \multirow{2}{*}{} & Jueves, 16 de febrero & 12 \\
\cline { 2 - 3 } & Lunes, 20 de febrero & 13 \\
\cline { 2 - 3 } & Jueves, 30 de marzo & 6 \\
\cline { 2 - 3 } & Lunes, 3 de abril & 25 \\
\hline \multirow{2}{*}{ Total } & 95 \\
\hline
\end{tabular}

Fuente: Elaboración propia con base en telediarios de la emisión estelar de Ecuador TV.

Se consideró además necesario someter los resultados a validez pragmática (Aigneren, 1999) mediante la contrastación con hechos. En este sentido, por ser noticias emitidas en el marco de procesos electorales de Ecuador, nos remitimos a la Ley Orgánica Electoral y de Organizaciones Políticas de la República del Ecuador Código de la Democracia, vigente desde el 29 de abril de 2009, que en su artículo 203 señala que los medios de comunicación se abstendrán de hacer promoción "directa o indirecta que tienda a incidir a favor o en contra de determinado candidato, postulado, opciones, preferencias electorales o tesis política".

La mayoría de las piezas informativas analizadas tienen relación con el contexto político en que se encontraba el país en el momento en que fueron elaboradas: tres procesos electorales presidenciales. De ahí que los temas recurrentes en las fechas previas a las votaciones fueran, entre otros, los cierres de campaña, información sobre las dignidades a elegir en las urnas, la ley seca (prohibición de vender y consumir bebidas alcohólicas), el silencio electoral, y los preparativos del proceso. En las fechas posteriores a las elecciones, las notas tuvieron relación con la proclamación de resultados, los incidentes ocurridos el día de las votaciones, diversas reacciones de figuras políticas y de la ciudadanía sobre los resultados, así como análisis del panorama político, social o económico del país

\subsection{Los informativos de 2009}

Las piezas seleccionadas muestran que el último día de campaña electoral (jueves 23 de abril de 2009) predominaron las notas de relevancia tópica, es decir, relacionadas con el tema del momento, en este caso con las elecciones del domingo 26. Buena parte de las notas son neutrales y basadas en hechos, como se muestra en porcentajes en la Figura 1. Además, las notas ofrecen una contextualización, y las entradillas denotan que los criterios de interés son principalmente la actualidad, la concienciación social y la notoriedad pública. Se ofrecen contenidos que invitan al público a acudir a las urnas de manera informada, a evitar infracciones por incumplir la Ley Electoral y, a, se da 
la palabra a varios ciudadanos para expresar su opinión general sobre los próximos comicios, sin emitir posturas a favor o en contra de candidatos específicos.

Figura 1. Porcentaje de notas informativas según contenidos, antes y después de las elecciones de 2009.

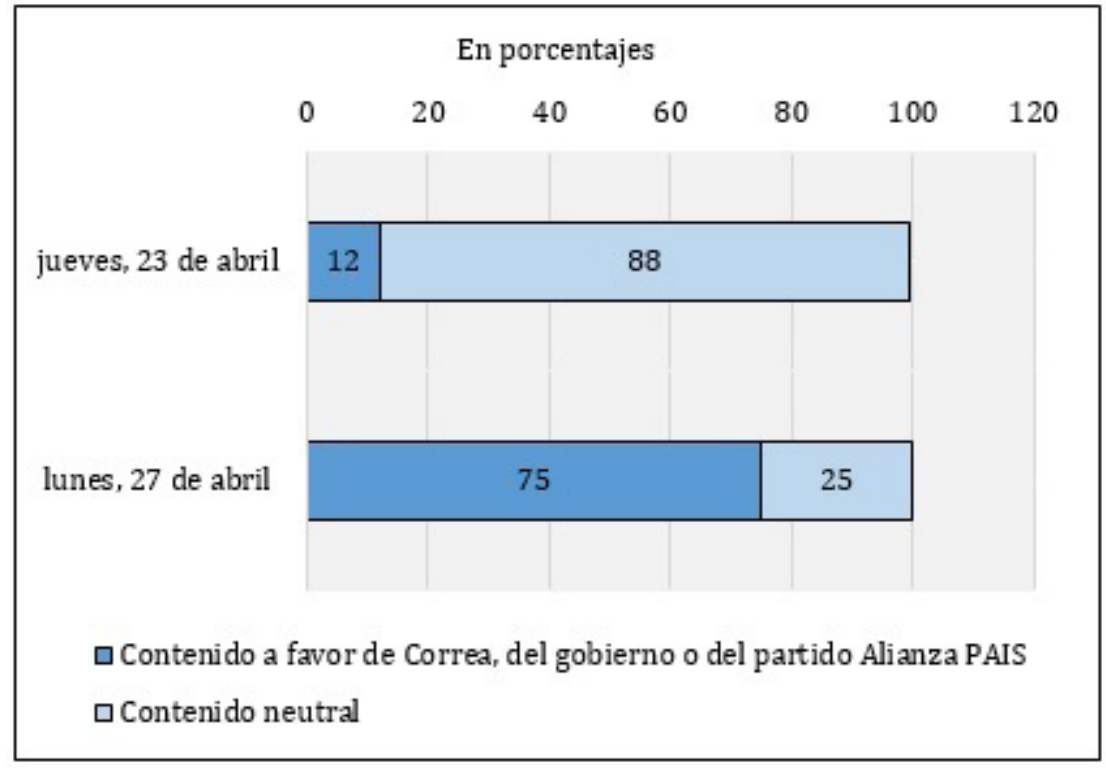

Fuente: Elaboración propia con base en telediarios de la emisión estelar de Ecuador TV.

En estas notas, que corresponden al $88 \%$ de la muestra, resalta un enfoque documental pues se ofrece una visión realista de la noticia a través de declaraciones (fuentes explícitas, consultadas y encuestadas) e información con diversos protagonistas como autoridades electorales, cuerpos de seguridad, agrupaciones políticas y ciudadanos, sin dejar de lado en ciertas notas el enfoque de interés humano, esto es, el punto de vista emotivo.

Solo una parte minoritaria de las piezas (el 12\%) presenta contenidos a favor del presidente-candidato Rafael Correa o hacia su gobierno. El telediario del prime time, de hecho, abre con una nota leída sobre los cierres de campaña, pero la edición del video dedica más segundos a Correa y a los candidatos del movimiento oficialista Alianza PAIS, mientras las imágenes de los postulantes de otros partidos políticos tienen poca duración y se limitan a tomas de sus recorridos en carro o a pie. A ello se suman el uso de términos con carga semántica como "euforia" o "pasión electoral", y el cierre de la nota nuevamente con Correa sobre una tarima y frente a una gran concurrencia que agita banderas verdes, que era el color de su partido. Se trata de una imagen positiva, porque ensalza la figura del candidato, y deja en el televidente la idea de un respaldo multitudinario o un virtual ganador.

En las piezas informativas del lunes 27 de abril, el día después de las elecciones, la distribución de los contenidos cambia en relación al jueves anterior. El protagonismo de Correa, de su gobierno y de su partido Alianza PAIS se incrementa pues ocupan más tiempo de emisión tras ser la opción que gana las elecciones del domingo. En el 75\% de las notas se percibe una intención de generar empatía de la audiencia hacia el presidente reelecto. Por ejemplo, la primera noticia consiste en la agenda de Correa durante el día en que se anuncia oficialmente su triunfo. El reportero usa frases y adjetivos que pueden contener conjeturas, tales como "el presidente tenía los sentimientos a flor de piel". Lo mismo ocurre cuando se da paso al reportaje principal sobre la visita del mandatario a una escuela en la que fallecieron varios niños, pues comienza con la frase "fueron momentos emotivos, de abrazos". 
Después que dos fuentes dan su testimonio, se presentan tomas de Correa llorando, mientras la narración (voz en off) dice: "también fue momento de lágrimas del mandatario", seguida de una pausa larga. Se insertan imágenes de menores de edad con uniformes de colegio mientras en el fondo hay carteles con el rostro del presidente, los niños abrazan a Correa y le cantan.

El resto de notas en las que se percibe una postura a favor de Correa tienen una estructura similar: se reitera el triunfo, se le da el protagonismo, no hay diversidad de fuentes y se emplean términos con carga semántica y adjetivos como "aplastante triunfo electoral" o "respaldo espontáneo de la población". Incluso, en una nota sobre el voto de los migrantes ecuatorianos en el exterior, la periodista informa: "extraoficialmente se sabe que los candidatos del movimiento PAIS tienen el más alto porcentaje de votación". Es decir, emite una información sin citar fuente o confirmar lo que declara.

\subsection{Los informativos de 2013}

En los telediarios de este año se percibe una estrategia política más articulada y directa -sin cuidar los formalismos- a favor del oficialismo, que buscaba otra reelección para gobernar cuatro años más, y en contra de sus adversarios. En las notas del último día de campaña (14 de febrero), Correa y sus actividades como presidente en funciones y como candidato tienen más duración dentro de la emisión del prime time, como se observa en porcentajes en la Figura 2. El cierre de su campaña, por ejemplo, es la nota de apertura del informativo estelar y tiene una duración de 2 minutos y 18 segundos. En ella se hace énfasis en las declaraciones del presidente en el último día de proselitismo. Se reitera, según sus propias declaraciones, que él ha realizado sus campañas "con los mismos zapatos, que están hecho huecos, el mismo cinturón y nunca he visto tanto entusiasmo, tanta esperanza como en esta elección". Así también, se incluye una de las frases más populares que enunciaba durante su mandato: "prohibido olvidar", aludiendo al pasado político y económico inestable del Ecuador, lo cual le da a la nota un enfoque personal y cargado de subjetividad.

Figura 2. Porcentaje de notas informativas según contenidos, antes y después de las elecciones de 2013.

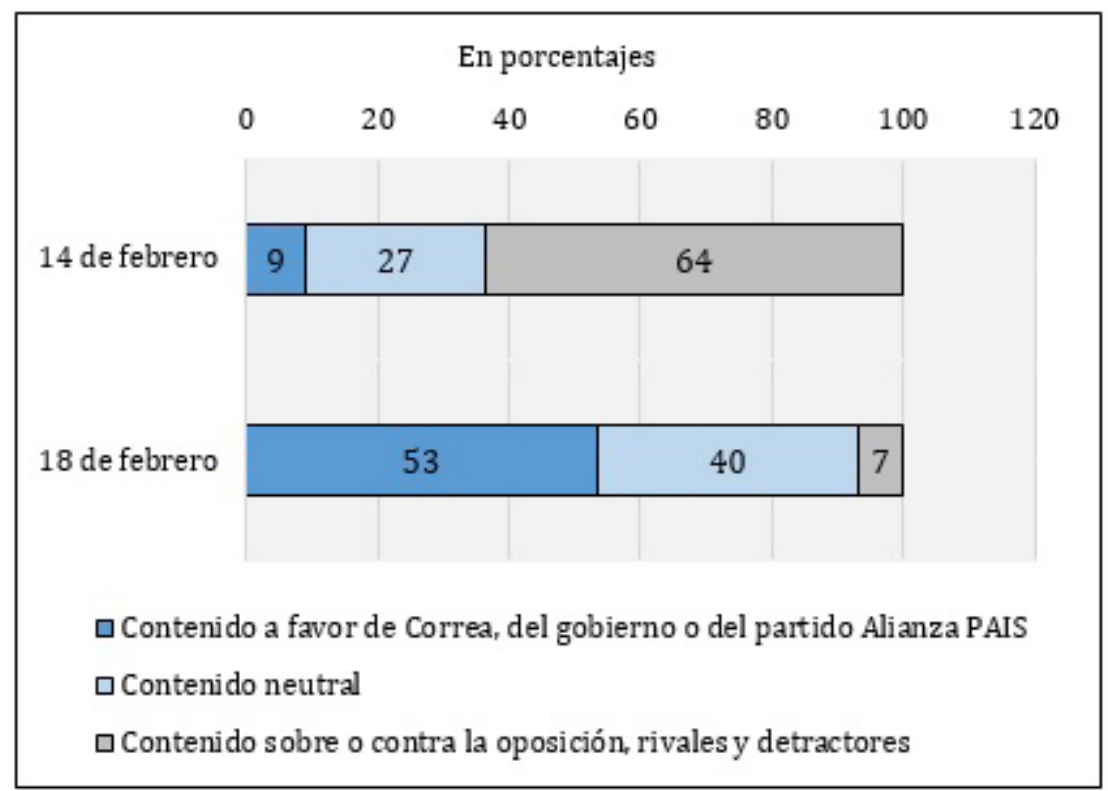

Fuente: Elaboración propia con base en telediarios de la emisión estelar de Ecuador TV.

Tras esta información, buena parte del telediario (64\% de la muestra) la componen piezas sobre los cierres de campaña de los candidatos de la oposición, pero el tiempo que se dedica a cada uno difie- 
re. Por ejemplo, al candidato Lucio Gutiérrez, quien fue Presidente del Ecuador de 2003 a 2005, se le dedican dos minutos, al igual que al empresario Álvaro Noboa, entonces en su cuarto intento por la Presidencia. Mientras, el telediario dedica a los demás postulantes entre minuto y medio y menos de un minuto, siendo en los últimos casos solo notas leídas: colas sin declaraciones de las fuentes interesadas o implicadas.

De los contenidos sobre los rivales cabe destacar la carga semántica negativa que se detecta en algunas de las piezas. Por ejemplo, sobre el cierre de campaña de Noboa en Guayaquil, el periodista culmina la nota con una conjetura, cuando dice: "este cierre de la campaña del PRIAN hubiera pasado por desapercibido de la urbe porteña si no se hubieran cerrado tantas avenidas de esta ciudad". En la pieza sobre Gutiérrez, el narrador remarca el liderazgo infructuoso del candidato cuando señala que los simpatizantes "demostraron su respaldo al ex presidente que busca retornar al puesto del cual salió el 20 de abril del 2005 tras una crisis del gobierno". A su vez, sobre el cierre de campaña de Alberto Acosta, quien fue parte del gobierno de Correa pero luego se enemistaron, la voz en off expresa: "Son seis mil personas y muchas más las que se quedaron fuera [de un coliseo]. Llegaron atraídos por la presencia del artista chileno Américo y por el cierre de campaña"; se daba a entender que la gente estuvo ahí principalmente por el show artístico.

En el informativo que se emite el lunes 18 de febrero tras las elecciones ocurre un giro: se observan una mayoría de piezas con contenidos a favor de Correa, su gobierno y Alianza PAIS, tras ganar los comicios; en concreto el 53\% de la muestra. Si bien la primera nota es neutral, pues se detallan los resultados electorales con gráficas y bajo un tono narrativo carente de juicios de valor, posteriormente las piezas tienen un enfoque personal subjetivo y de interés humano que busca el punto de vista emotivo. Se emplean expresiones con carga semántica; por ejemplo, cuando un reportero indica que "la Plaza de la Independencia vivía una algarabía mayor a la usual", o que "el comercio informal vistió de verde alianza". También se detecta un frame conjetural, cuando en una nota sobre los resultados electorales en España, donde votó la comunidad migrante ecuatoriana, la autora hace alusión a la gestión del gobierno como un factor que incidió en la reelección.

En general, en las notas se busca generar empatía con el presidente reelecto, insertando una conversación casual con él para reflejar su lado humano y cercanía con las personas mediante testimonios de ciudadanos e imágenes de ellos respaldándolo en las calles. No solo en los reportajes se percibe esta postura, sino también en las entradillas, donde la palabra "triunfo" o "victoria" se enuncian constantemente. Las fuentes que más se citan están relacionadas con el partido de Correa y se difunden felicitaciones de otros jefes de Estado de la región. Además, se complementan las noticias con voces de sociólogos y expertos que analizan el triunfo oficialista y cuyas opiniones son todas a favor, en un claro ejercicio de propaganda blanca.

Cabe señalar que en este telediario también se emite una nota de dos minutos y medio, titulada "La caída de la hegemonía de los partidos tradicionales en el Congreso". Aparenta ser una pieza de análisis histórico sobre los cambios de grupos de poder en el Legislativo, pero incurre en propaganda gris al ser de dudosa procedencia pero con una intención clara. Aquí el narrador emite juicios de valor cuando señala: "en el Congreso de 1998, ese en el que era muy común escuchar insultos entre colegas y observar hechos desagradables"; también se habla de "los grandes perdedores del domingo". Además, acompaña la nota con imágenes de personajes de la oposición y con fuentes sesgadas, entre ellas, un analista político que declara: "Rafael Correa ha terminado hundiéndoles (...); la demagogia ya no tiene lugar en este país"; ante lo cual finalmente el periodista recalca: "los expertos concuerdan que esta elección fue el acta de defunción de lo que algún día conocimos como la partidocracia”.

De hecho, "partidocracia" era un término recurrente usado por el entonces presidente Correa para referirse a otros partidos políticos y a sus principales figuras que, según él, habían gobernado Ecuador desde el retorno a la democracia en 1979 y mantenido al país en la pobreza. En la década que 
gobernó Rafael Correa esa palabra fue tan usada en sus discursos que la carga negativa estaba ampliamente insertada en la opinión pública.

\subsection{Los informativos de 2017}

En los informativos analizados antes y después de los procesos electorales de este año, en los que hubo necesidad de segunda vuelta o balotaje, se perciben escasos esfuerzos del canal público por desarrollar piezas neutrales o equilibradas en las temáticas de Actualidad y Política, tal como se muestra en los porcentajes de la Figura 3.

Aunque Correa no es candidato en estas elecciones, su presencia en el informativo de Ecuador TV es central. Se acentúan los discursos en torno a la continuidad de su gobierno y las obras realizadas durante su mandato, y se refleja que es el presidente en funciones quien activamente lidera la campaña para que Lenín Moreno, abanderado por el partido oficialista, le suceda en el poder. Moreno había sido vicepresidente de Correa por seis años y luego embajador ante la ONU en Ginebra.

Figura 3. Porcentaje de notas informativas según contenidos, antes y después de las elecciones (primera y segunda vuelta de 2017).

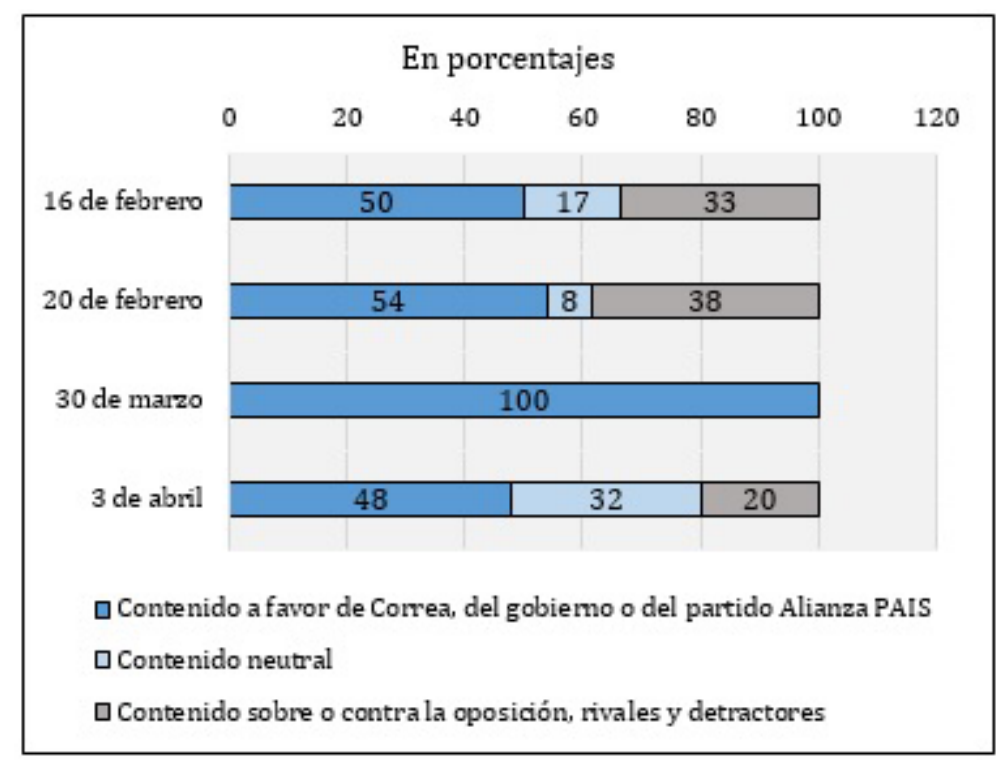

Fuente: Elaboración propia con base en telediarios de la emisión estelar de Ecuador TV.

En la primera vuelta, el noticiero del último día de campaña (16 de febrero) evidencia una mayor cantidad de notas informativas sobre el binomio de Lenín Moreno y Jorge Glas, hasta llegar al 50\% de la muestra (Figura 3). La primera pieza, por ejemplo, contiene un extracto del candidato Moreno que dura más de cuatro minutos, superando al resto de soundbites usados en el telediario. Además, en otras notas se resalta lo realizado durante la autodenominada "década de la Revolución Ciudadana". Una es un reportaje sobre la inauguración simultánea de dieciséis "escuelas del milenio", que se construyeron en el mandato de Correa. En él se incluyen entrevistas a funcionarios y cifras de inversión, matizadas con una carga emocional de imágenes de niños y el mandatario aún en funciones, juntos en un salón de clases. En otro espacio, y con la claqueta de "Mirada Global", un ex funcionario del gobierno (fuente implicada) expresa, con tono positivo y enfoque perspectivista, que "lo que se definirá para la ciudadanía ecuatoriana es la certeza de avanzar o el riesgo de retroceder".

Cabe señalar que el telediario presenta también un directo (declaración) de casi dos minutos de Correa, quien denuncia una "campaña sucia" que intenta desestabilizar al binomio de su partido. Esta 
pieza, en particular, reúne varios elementos cuestionables periodísticamente. Se basa en conjeturas, pues el protagonista de la nota, aunque sea el presidente, lanza información acusatoria sin señalar la fuente. Así incurre en propaganda negra, pues no se sabe quién la origina y podría ser falsa. A su vez, el medio la reproduce sin contextualizar ni contrastar, pues se da relevancia al conflicto y a la especulación, como se ve en el siguiente extracto de esa transmisión:

Esto, lo que hemos obtenido es de gente honesta, asqueada de ver tanta campaña sucia (...) Esas fuentes humanas nos han informado que mañana, en un último y desesperado intento, porque saben lo que les espera el próximo domingo (...) van a sacar otra bomba y detrás de ellos están los Isaías (...); estén preparados ante esta nueva bomba que preparan los hermanos Isaías (...), otra mentira más para intentar alterar las elecciones.

Se insertan también otras piezas (el $33 \%$ de la muestra) de fuente dudosa pero claramente enfocadas en desprestigiar a detractores. Una trata sobre los hermanos Isaías, ex dueños de Filanbanco y de un conglomerado de medios incautados por el gobierno, en la que se señala que, junto a ciertos candidatos, están conspirando para desestabilizar al gobierno. Otra nota habla de un supuesto complot de la Central de Inteligencia Americana (CIA) junto a ciertos medios de comunicación internacionales, para forzar una segunda vuelta electoral en Ecuador. Dentro de la nota se ataca al candidato de la oposición, Guillermo Lasso, dueño del Banco de Guayaquil, a quien se acusa de tener cuentas offshore. Todo este segmento tiene una carga semántica que se puede leer desde el tono de los presentadores en las entradillas, quienes se refieren al candidato como "el banquero".

En el telediario del 20 de febrero, el día después de las elecciones, se dedica más de la mitad de las piezas sobre política y actualidad (en concreto, el 53\% de la muestra) a la victoria de Moreno en primera vuelta, aunque este hecho no había sido todavía confirmado por el Consejo Nacional Electoral. El reportero, citando a Moreno, indica que "a su criterio es una victoria contundente de Alianza PAIS", y agrega que el candidato "rechazó los llamados a la violencia que surgen de la candidatura opositora y otras tiendas políticas"; esto se relaciona con una noticia presentada previamente que narra disturbios provocados por simpatizantes y postulantes de los otros partidos que denunciaban irregularidades en el conteo. Todos los entrevistados de las notas a favor del virtual ganador son del partido oficialista, y hasta el presidente del CNE acude al set de Ecuador TV para una entrevista en vivo, en la cual defiende la transparencia del proceso y desmiente que exista fraude. La duración de esta comparecencia es de casi 13 minutos.

Esta estrategia política se evidencia en los demás contenidos del telediario, particularmente porque Moreno no ganó en una sola vuelta electoral, dado que la ley establece que se necesita la mitad más uno de los votos, como lo logró Correa en sus dos reelecciones en 2009 y 2013; de ahí que, al existir balotaje, se acentuó el uso de la maquinaria estatal -medios públicos incluidos-para afianzar la idea de una victoria. Se destacan en estas piezas informativas los logros del gobierno. Por ejemplo, los dirigentes del partido oficialista aplauden en un reportaje los resultados en la provincia de Manabí, la tercera en importancia del país. Esta provincia fue devastada por un terremoto en abril de 2016, por lo que se le da un espacio para presentar los testimonios de habitantes agradecidos por la ayuda del gobierno para recuperarse de la tragedia. El informativo resalta el deseo de los habitantes de que "continúe de la misma manera", aludiendo al mandato de Correa y evocando su perpetuidad a través de Moreno.

En cuanto a las notas con contenidos referentes a la oposición, que alcanzan un $38 \%$ de la muestra, se destaca el uso de adjetivos como "derrota", "perdedor", "banquero", así como un frame donde prima el enfrentamiento. Las piezas recogen imágenes de agresiones por parte de militantes de los grupos políticos contrarios, como parte de sus reclamos ante los resultados. Se acompaña este discurso visual con expresiones de algunas autoridades como: "este tema no puede ser de quien grita más, o quien tiene un capricho más, o quien insulta (...); las elecciones no se ganan con especulaciones, se ganan con votos". 
En las emisiones del prime time de Ecuador $T V$ previo a las elecciones de la segunda vuelta, la carga informativa se concentra en la promoción del binomio Moreno-Glas. Prácticamente la totalidad de las piezas incurren en propaganda blanca, y se siguen empleando calificativos como "masiva" o "contundente" para describir el cierre de campaña de Moreno. Asimismo, se usan palabras con carga semántica como "respaldo", "continuidad", "apoyo", y "mentiras de la derecha" en las siguientes noticias. Además, las piezas tienen un enfoque reactivo, es decir, basadas en la respuesta o reacción de los principales protagonistas, pues se incluye una recolección de directos de hasta nueve diferentes organizaciones sociales que anuncian su apoyo incondicional al nuevo binomio presidencial. El tono narrativo de los periodistas también contribuye al discurso claramente sesgado.

Después de las elecciones del domingo 2 de abril, el informativo estelar de Ecuador TV incluye en la mitad de su emisión un espacio editorial de más de dos minutos de duración. Este tiene un tono personal, y la carga semántica se percibe en las palabras del presentador, cuya intención es ofrecer una postura del canal público sobre la errónea proclamación del candidato Lasso como ganador de las elecciones, que medios privados habían transmitido el día anterior. En este segmento, el presentador expresa:

No se puede seguir comunicando sin hacernos cargo de lo que decimos. Lo que pasó ayer fue muy grave. Que nunca más, por muy poderosos que se crean determinados emisores, se proclamen ganadores sólo porque a ellos les conviene o porque así lo planearon.

Situando esta intervención en contexto, el mensaje reviste mayor importancia y confrontación. Quien emite la opinión es Xavier Lasso, Gerente Editorial de los Medios Públicos del Ecuador, ex canciller en el gobierno de Correa y, además, hermano del candidato cuestionado. Cabe señalar que el ambiente en Ecuador era bastante complejo en las horas siguientes del cierre de las urnas, pues los resultados de la elección en segunda vuelta tuvieron una diferencia mínima.

Buena parte de las notas de ese lunes posterior a las elecciones ( $48 \%$ de la muestra), se centran en el binomio ganador y reiteran el discurso de continuidad. Se usan imágenes de Correa, Moreno, Glas y simpatizantes, junto a testimonios de ciudadanos que aseguran que "es una década ganada", "vamos a continuar el proceso de Revolución", etc.

Este tratamiento se visualiza también en los contenidos dedicados a la oposición, que alcanzan un $20 \%$ de la muestra. Por ejemplo, hay una nota sobre una rueda de prensa en la que Guillermo Lasso declara que "no reconocemos ni aceptamos los resultados", y se niega a responder preguntas del canal público, al cual acusa de sesgado. Aquí, el periodista autor de la nota narra: "cuestionó nuestra pregunta por ser un medio público". Aunque hubo otras piezas abordadas de manera neutral (un $32 \%$ ), en el resumen del noticiero en lengua de señas y en idioma quichua, que también es oficial en Ecuador, únicamente se mostraron notas positivas referentes a la transparencia de las elecciones y al triunfo del oficialismo.

\section{Discusión de resultados y conclusiones}

Del total de 95 piezas analizadas en los telediarios de la noche, 68 notas (el 71,5\% de la muestra) presentan elementos que incurren en propaganda y falta de equilibrio o de contraste. De este grupo, 46 piezas muestran posturas a favor de la campaña de Correa y de su gobierno, dedicando además espacios a destacar la organización de los comicios y a defender la transparencia de los resultados, mientras que en las 22 notas restantes se observan posturas sesgadas contra los candidatos de la oposición o detractores del oficialismo. Las demás piezas de la muestra (el 28,4\%) presentan un tratamiento neutral. En estos casos se trata principalmente de notas en las que se difunden los preparativos sobre los comicios, cómo se realizó la jornada, avances de resultados del conteo de los votos 
con fuentes oficiales, reportes internacionales y otros temas en los que no se percibe una deliberada estrategia política de propaganda.

Estos resultados permiten afirmar que los contenidos informativos sobre temas políticos en Ecuador TV tuvieron un notable y marcado papel propagandístico durante las campañas presidenciales en el mandato de Rafael Correa. El análisis de los telediarios arroja resultados y características comunes: por lo general, carecen de equilibrio y de contraste de fuentes; falta contextualización de las noticias o, si se hace, se trata de datos que repercuten negativamente en la imagen de la oposición; se usan adjetivos o palabras que añaden una carga semántica y enmarcan el enfoque de las noticias; y se destina una mayor cantidad de tiempo al partido de Rafael Correa. En síntesis, abundan noticias disfrazadas de propaganda en diversas intensidades, lo cual no corresponde a la función teórica de un medio público, que debe caracterizarse por la independencia, el equilibrio y el pluralismo, según la propia legislación del país lo exige en el Código de la Democracia de 2009.

En la estrategia de Correa los medios públicos, que en principio representaban una respuesta a la concentración de medios privados y a la necesidad de una comunicación plural, se convirtieron en parte de un aparato diseñado para consolidar un Estado comunicador o de propaganda con el propósito de consolidar el gobierno y su popularidad. Un rasgo común de los regímenes de la nueva izquierda latinoamericana, Correa incluido, fue precisamente el gran protagonismo de sus líderes políticos como actores comunicacionales, y su áspera relación con periodistas independientes y medios privados.

Los nuevos marcos regulatorios de la comunicación facilitaron la ejecución de esas estrategias por parte de lo que se ha dado en llamar, por la fuerte impronta que dejó su líder político, correísmo. En el caso de Ecuador TV existieron además otras normas, en especial las relativas a las cadenas nacionales, que propiciaron la adopción de un papel propagandístico clave. En su virtud, todos los demás medios audiovisuales eran obligados a conectar con Ecuador TV para dar la versión oficial de los hechos. El entramado de medios creado por los gobiernos de Correa, particularmente en el ámbito audiovisual, favoreció sus intereses políticos de permanencia en el poder. Desde este punto de vista la operación fue exitosa y culminó además en la elección de su sucesor Lenín Moreno, amparado por su partido. Sin embargo, desde una perspectiva periodística y empresarial, la red de medios organizada se fue diluyendo tras su marcha dado que resultaba financieramente insostenible. De toda ella quedó solo, como mayor aportación, precisamente Ecuador TV.

El análisis de la propaganda en el régimen de Correa puede verse enriquecido con estudios acerca de la cobertura de Ecuador TV de otros procesos electorales no presidenciales, así como la realizada por otros canales no públicos, que permitirían una visión comparada. No obstante, debe advertirse a este respecto que la labor de obtención de los telediarios analizados en este artículo fue complicada y las gestiones duraron meses. Su visionado permitió, al mismo tiempo, depurar y afinar las variables finalmente expuestas, que se ofrecen aquí también como un posible modelo para analizar los contenidos de piezas y programas informativos en televisión.

El modelo de televisión pública creada en Ecuador y la estructura resultante del entero sector audiovisual pueden ser asimismo objeto de ulteriores estudios comparativos que las pongan en discusión con otras existentes en la región, lo cual desborda el objetivo principal de este trabajo que, no obstante, proporciona elementos de interés para dichos análisis.

\section{Bibliografía}

Aigneren, M. (1999). Análisis de contenido: una introducción. La Sociología en sus escenarios, 3, 1-52. https://revistas.udea.edu.co/index.php/ceo/article/view/1550

Albán, M. E. (2016). La calidad de la información y el debate por la "verdad" en medios públicos y privados en Ecuador. Iuris, 15(1), 73-101. http://dspace.ucuenca.edu.ec/ bitstream/123456789/27746/1/3.pdf 
Badillo, A., Mastrini, G. y Marenghi, P. (2015). Teoría crítica, izquierda y políticas públicas de comunicación: el caso de América Latina y los gobiernos progresistas. Comunicación y Sociedad, 24, 95-126. https://doi.org/10.32870/cys.v0i24.2524

Becerra, M. y Waisbord, S. (2015). Principios y "buenas prácticas" para los medios públicos en América Latina. Unesco. http://www.unesco.org/new/fileadmin/MULTIMEDIA/FIELD/ Montevideo/pdf/CDCI3-Becerra-ES.pdf

Checa, F. y Barredo, D. (2016). Ley de comunicación, medios púbicos y libertad de expresión en Ecuador: una mirada desde los periodistas. ALAIC Revista Latinoamericana de Ciencias de la Comunicación, 13, 36-47. https://www.researchgate.net/publication/312167526_Ley_de comunicacion_medios_publicos_y_libertad_de_expresion_en_Ecuador_una_mirada desde los periodistas

Checa-Godoy, A. (2012). La banca y la propiedad de los medios: el caso de Ecuador. Revista Latina de Comunicación Social, 67(2), 125-147. http://dx.doi.org/10.4185/RLCS-067-950-125-147

Conaghan, C. y De la Torre, C. (2008). The Permanent Campaign of Rafael Correa: Making Ecuador's Plebiscitary Presidency. The International Journal of Press/Politics, 13(3), 267-284. https://doi.org/10.1177/1940161208319464

Cunningham, S. B. (2002). The idea of propaganda: a reconstruction. Praeger.

De la Torre, H. S. (2013). Historia de un medio público: caso Radio Nacional del Ecuador (Tesis doctoral). Universidad Central del Ecuador, Quito. http://www.dspace.uce.edu.ec/handle/25000/2661

El Universo (29 de noviembre de 2007). Canal estatal inició transmisión con entrevista a Correa. https://www.eluniverso.com/2007/11/29/0001/8/CE339941B5EB439DA2F5690377A1F1AB.html

Ellul, J. (1973). Propaganda: the formation of men's attitudes. Random House.

Fundamedios (2010). La palabra rota: seis investigaciones sobre periodismo ecuatoriano. https:// www.fundamedios.org.ec/la-palabra-rota-seis-investigaciones-sobre-el-periodismo-ecuatoriano/

Gerbner, G. (1970). Cultural indicators: the case of violence in television drama. The Annals of the American Academy of Political and Social Science, 338 (1), 69-81. https://doi. org/10.1177/000271627038800108

Goodman, N. (1976). Languages of art: an approach to the theory of symbols. Hackett Publishing.

Jowett, G. S. (2008). Propaganda, Visual Communication of. En W. Donsbach (Ed.). The International Encyclopedia of Communication, IX, 3919-3925. https://doi.org/10.1002/9781405186407.wbiecp110

Jowett, G. S. y O’Donnell, V. (2012). Propaganda and Persuasion (5 ed.). Sage.

Kitzberger, P. (2010). Giro a la izquierda, populismo y activismo gubernamental en la esfera pública mediática en América Latina. En B. Sorj (Comp.), Poder político y medios de comunicación: de la representación política al reality show (pp. 61-100). Siglo XXI.

Lasswell, H. D. (1927). Propaganda Technique in the World War. Knopf.

Maldonado, C. (2017). El noticiero central del canal público Ecuador TV: cerca del gobierno, lejos de la ciudadanía (Tesis de maestría). Universidad Andina Simón Bolívar, Quito. https:// repositorio.uasb.edu.ec/bitstream/10644/5897/1/T2464-MC-Maldonado-El\%20noticiero.pdf

Marlin, R. (2002). Propaganda and the Ethics of Persuasion. Broadview Press. 
Mastrini, G. (2011). Medios Públicos y derecho a la comunicación: una aproximación desde América Latina. Lecciones del Portal de la Comunicación InCom-UAB. https://incom.uab.cat/ portalcom/wp-content/uploads/2020/01/65_esp.pdf

Mier, A. C. (2015). Creación y desarrollo de Ecuador TV (Tesis doctoral). Universidad de Santiago de Compostela. https://minerva.usc.es/xmlui/handle/10347/14598

Natanson, J. (2010). La nueva izquierda latinoamericana frente a los medios de comunicación: una relación compleja. Temas y Debates 14(20), 61-67. https://core.ac.uk/download/pdf/61698923.pdf

Ortega, P. (2010). Televisión Pública en América Latina: los valores del mercado y las políticas del Estado. Infoamérica: Iberoamerican Communication Review, 21(3-4), 205-213. https://www. infoamerica.org/icr/n03 04/ortega.pdf

Ortega, F. y Galhardi, C. (2013). Propuesta metodológica para el análisis de contenido de la parrilla de televisión en Brasil. En M. Vicente-Mariño, T. González-Hortigüela y M. PachecoRueda (Coords.). Investigar la comunicación hoy: revisión de políticas cientificas y aportaciones metodológicas. Vol. 1 (pp. 221-240). https://dialnet.unirioja.es/servlet/articulo?codigo=4228799

Panchana, A. y Mena, L. (2020). El mapa de los medios públicos de Ecuador: entre el auge y la ambigüedad. Global Media Journal México, 17(32), 42-59. https://doi.org/10.29105/gmjmx17.32-3

Páramo-Bernal, P. (Comp.) (2018). La investigación en ciencias sociales: técnicas de recolección de la información. Bogotá. https://doi.org/10.2307/j.ctv7fmfjk

Ramos, H. (2010). Medios públicos y poder político en la era de Rafael Correa. En Fundamedios, La palabra rota: seis investigaciones sobre el periodismo ecuatoriano (pp. 209-216). https:// www.fundamedios.org.ec/la-palabra-rota-seis-investigaciones-sobre-el-periodismo-ecuatoriano/

Ricaurte, C. (2009, 8 de julio). De tropezón en tropezón. HOY. http://estemalditopais.blogspot. $\underline{\mathrm{com} / 2009 / 07 / ? \mathrm{~m}=0}$

Soules, M. (2015). Media, Persuasion and Propaganda. Edinburgh University Press.

Souza, B. (2010). Hablemos del Socialismo del Buen Vivir. http://www.plataformabuenvivir.com/ wp-content/uploads/2012/07/SouzaSantosSocialismoBuenVivir2010.pdf

Suing, A. R. (2011). El Consejo de Comunicación del Ecuador. Creación, organización, debate y análisis comparativo (Tesis doctoral). Universidad de Santiago de Compostela. https://minerva. usc.es/xmlui/bitstream/handle/10347/3715/SuingRuiz.pdf?sequence=1\&isAllowed=y

Stornaiolo, U. (2019). Las relaciones entre Rafael Correa y la prensa ecuatoriana en el período 2006-2017. Textos y Contextos, 18, 51-59. https://doi.org/10.29166/tyc.v0i18.1739

Werner, H. y Kaplan, B. (1963). Symbol formation: an organismic developmental approach to language and the expression of thought. John Wiley \& Sons.

Wilke, J. (2008). Propaganda. En W. Donsbach (Ed.). The International Encyclopedia of Communication, IX, 3915-3919. https://doi.org/10.1002/9781405186407.wbiecp109

Zepeda, B. (2010). Construyendo la nación en el siglo XXI: la "patria" en el discurso del presidente Correa. En F. Burbano (Comp.). Transiciones y rupturas: el Ecuador en la segunda mitad del siglo XX (pp. 159-193). FLACSO. https://www.researchgate.net/ publication/314516392_Construyendo_la_nacion_en_el_siglo_XXI_La_\%27patria\%27 en_el_ discurso_del_Presidente_Correa 